\title{
Experimental and Numerical Study of Thermal Stability and Fire Performance of Brominated and Halogen-free Flame Retardants in Glass-fibre Reinforced Poly(butylene terephthalate)
}

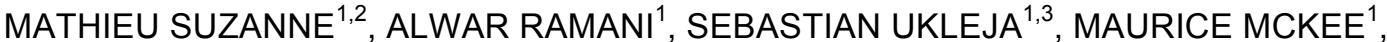 \\ JIANPING ZHANG ${ }^{1}$, MICHAEL DELICHATSIOS ${ }^{1}$ and DIMITRI BAKIRTZIS ${ }^{1}$ \\ ${ }^{1}$ University of Ulster, Shore Road, Newtownabbey, BT37 0QB, UK \\ ${ }^{2}$ Central Laboratory of Police Prefecture, 39bis rue de Dantzig, 75015, Paris, France \\ ${ }^{3}$ Centrum Techniki Okretowej S.A., Ship Design and Research Centre, Szczecinska 65,80-392, \\ Gdansk, Poland
}

\begin{abstract}
This paper investigates the effects of brominated and halogen-free fire retardants on the thermal stability and fire performance of glass-fibre reinforced poly(butylene terephthalate). Brominated polystyrene was used as the brominated fire retardant (BFR), whereas aluminium diethylphosphinate (Alpi) with/without nanoclay as halogen-free fire retardants (HFFRs). Tests were conducted using thermogravimetric analysis (TGA), limiting oxygen index (LOI), UL94 and the cone calorimeter. TGA results show that decomposition of glass-fibre plus PBT (PBT+GF) starts earlier in the presence of fire retardants (FRs). In the cone calorimeter, all FRs reduce significantly the heat release rate (HRR) compared to PBT $+\mathrm{GF}$, with brominated polystyrene achieving lower HRR primarily because bromine released in the pyrolysis gases inhibits combustion, without however changing the mass loss rate (MLR). Alpi alone has significant effects on reduction of both HRR and MLR, which become considerably more when combined with nanoclay. The efficiency of combustion of the brominated polystyrene compound is much lower than that of HFFRs, which indicates that unburned pyrolysing gases are released during the combustion of brominated fire retardants.
\end{abstract}

KEYWORDS: brominated fire retardants, halogen-free fire retardants, thermogravimetric analysis, cone calorimeter

\section{INTRODUCTION}

In the past few years, the environmental and toxicological hazards of brominated flame retardants (BFRs) have been highlighted in several studies [1-7]. It was demonstrated in [1-5] that (i) some of the BFRs result in a strong bioaccumulation in aquatic and terrestrial food chains, and (ii) a growing number of BFRs is found in increasing concentrations in the human food chain, human tissues and breast milk. Furthermore, BFRs have also been found in indoor environment such as in dust at homes [6]. BFRs are persistent showing serious toxicological effects such as endocrine disruption. Brain and nervous system were identified as one of the most vulnerable targets for the toxic actions PBDE's [7]. It is therefore not surprising that some of BFRs are or will be soon phased out. Consequently it is essential, for ecological and economic reasons, to investigate available environmental friendly alternatives. However, banning specific BFRs may imply a serious risk if the introduction of non-brominated alternatives is not properly assessed regarding its impact on environment and human health. It is also of vital importance that the substitution options do not affect the functionality and reliability of the end product, including the fire behaviour. It has been shown in [8-10] that BFRs can reduce significantly the heat release rate because when the brominated material burns, the flame retardant produces hydrobromic acid which interferes in the radical chain reaction of the oxidation reaction of the fire. The mechanism is that the highly reactive hydrogen radicals, oxygen radicals, and hydroxy radicals react with hydrobromic acid to form less reactive bromine radicals (i.e., free bromine atoms).

This paper presents an evaluation of alternatives for brominated polystyrene in glass-fibre reinforced poly(butylene terephthalate) $(\mathrm{PBT}+\mathrm{GF})$ for its fire retardancy. $\mathrm{PBT}+\mathrm{GF}$ was fire retarded with either brominated polystyrene combined with antimony trioxide or aluminium diethylphosphinate (Alpi) with/without organically modified montmorillonite clay (OMMT). The main fire retardant mechanism of Alpi is that it intumescences upon heating, forming a thick intumescent layer that protects the unpyrolysed material from heating and thus pyrolysis[11,12]. Nanoclays, while having limited effect on degradation of 
polymers in thermogravimetric analysis (TGA) where mg samples are used, have also been shown to have an important effect in reduce the heat release rate/mass loss rate in the cone calorimeter, owing to the formation of a surface layer after polymer composites degrade and nanoparticles are left behind or to increased strength and integrity of the char when nanoclays are added to FRs (phosphorus-based or intumescent coatings) [13-15].

In this work, thermal decomposition, flammability and fire tests were conducted using a combination of thermogravimetric analysis (TGA), limiting oxygen index (LOI), UL94 and the cone calorimeter in both horizontal and vertical orientations. Flammability properties are determined from the ignition tests and comparative analyses were made in terms of mass loss in TGA and time to ignition, heat release rate, mass loss rate, production of carbon monoxide and smoke in the cone calorimeter. The effect of glass-fibre in the PBT formulation is also examined using a numerical model previously developed for polymer nanocomposites.

The paper is organized in the following way. First, the materials information is given, along with experimental details. Next, experimental results and discussions are presented followed by the conclusions of this work.

\section{MATERIALS}

In total, four formulations were investigated as shown in Table 1. The base formulation, PG1, consists of PBT reinforced with $30 \mathrm{wt}$. \% of glass-fibre. A halogenated formulation, PG2, contains 10 wt. \% brominated polystyrene (BrPS), with 5 wt. \% antimony trioxide for synergism as normally done. In addition, two halogen-free flame retardants (HFFRs) were studied: PG4 contains $15 \mathrm{wt} \%$ aluminium diethylphosphinate (Alpi) and PG3 15.5 wt. \% Alpi with 2.5 wt. \% organically modified montmorillonite clay (OMMT).

Table 1. Summary of the formulations and their compositions studied in this work.

\begin{tabular}{|l|l|l|l|l|l|}
\hline \multirow{2}{*}{ Compounds } & \multicolumn{3}{|l|}{$\%$ weight of formulations } & \multirow{2}{*}{ Commercial product name and suppliers } \\
\cline { 2 - 6 } & PG1 & PG2 & PG3 & PG4 & \\
\hline PBT+GF & 100 & 85 & 82 & 85 & Arnite TV4 261 from DSM \\
\hline Brominated polystyrene & 0 & 10 & 0 & 0 & Milebrome 7010 from MPI Chemie \\
\hline Antimony trioxide & 0 & 5 & 0 & 0 & Timonox Red Star from Chemtura \\
\hline Alpi & 0 & 0 & 15.5 & 15 & Exolit OP 1230 from Clariant \\
\hline OMMT & 0 & 0 & 2.5 & 0 & $\begin{array}{l}\text { Cloisite 30B from Southern Clay } \\
\text { Products }\end{array}$ \\
\hline
\end{tabular}

Prior to extrusion, the virgin polymer and fire retardants were dried at $120^{\circ} \mathrm{C}$ under vacuum in an oven for 6 hours. A Prism Twin Screw Extruder (TSE) 16 TC was used to produce the plate samples in the cone calorimeter. The temperatures corresponding to the rear, centre and front zones were $240{ }^{\circ} \mathrm{C}, 245{ }^{\circ} \mathrm{C}$ and $255^{\circ} \mathrm{C}$, respectively, and the screw speed was set at $60 \mathrm{rpm}$. The extruded polymer was then pelletised and dried. A BOY $22 \mathrm{M}$ injection moulding machine was utilized to mould the samples. The temperatures corresponding to the rear, centre, front and nozzle zones were $240^{\circ} \mathrm{C}, 250^{\circ} \mathrm{C}, 250^{\circ} \mathrm{C}$, and $260^{\circ} \mathrm{C}$, respectively. These temperatures were varied by $\pm 5^{\circ} \mathrm{C}$ depending on the level for the fire retardant present. The melt temperature was $255^{\circ} \mathrm{C}$ and the water-cooled mould was set at $80^{\circ} \mathrm{C}$. The thickness of the cone samples is $2.9 \mathrm{~mm}$ with a surface area of $0.1 \times 0.1 \mathrm{~m}^{2}$. No measurements of the polydispersity of nanoparticles were made.

\section{EXPERIMENTAL DETAILS}

\section{Thermogravimetric Analysis (TGA)}

Thermal analysis was performed using a Mettler Toledo TGA/STDA 851e measuring module, with temperature accuracy and temperature reproducibility of $\pm 0.5^{\circ} \mathrm{C}$. Samples of around $10 \mathrm{mg}$ were heated in alumina pans at three heating rates, i.e., 5,10 and $20{ }^{\circ} \mathrm{C} / \mathrm{min}$, from 300 to $1000{ }^{\circ} \mathrm{C}$ in nitrogen with a flow rate of $50 \mathrm{~cm}^{3} / \mathrm{min}$. The results at different heating rates have similar trends and thus only the ones at $10^{\circ} \mathrm{C} / \mathrm{min}$ are presented in this paper. 


\section{Limiting oxygen index (LOI) and UL94}

LOI measurements and UL94 vertical tests were conducted using $3.2 \mathrm{~mm}$ thick samples, according to BS EN 60695-11-10 and BS EN ISO 4589-2, respectively. Due to the complexity of tests, a varied number of tests were conducted for each formulation, with a minimum of five specimens used for any of the tests.

\section{Cone calorimeter}

Tests were conducted at six heat fluxes in horizontal orientation $\left(22.5,30,45,60,75\right.$ and $\left.90 \mathrm{~kW} / \mathrm{m}^{2}\right)$ whereas at one in vertical orientation $\left(75 \mathrm{~kW} / \mathrm{m}^{2}\right)$ in order to assess the strength of the char and the effects of orientation. At each heat flux, tests were repeated at least three times to ensure repeatability. Time to ignition (TTI), heat release rate (HRR), mass loss rate (MLR) and production of carbon monoxide, carbon dioxide and smoke were recorded. During the tests, the exposed surface of the plates was covered with carbon black to ensure maximum surface absorption of external heat with absorptivity close to one. Before the tests, all samples were kept in a conditioning room maintained at an atmosphere of $50 \pm 5 \%$ of relative humidity and at $23 \pm 2{ }^{\circ} \mathrm{C}$ until their mass was stabilized. All the experiments were carried out with an insulation consisting of four layers of low-conductivity Cotronic paper at the back and sides of the specimen in order to reduce heat losses to the sample holder [16]. Aluminium foil was used to avoid melted polymer to soak into the Cotronic insulation paper.

\section{RESULTS AND DISCUSSIONS}

\section{Thermogravimetric Analysis (TGA)}

Figure 1 shows a comparison of the mass loss history at $10{ }^{\circ} \mathrm{C} / \mathrm{min}$ between PG1 (i.e, PBT reinforced with glass-fibre) and neat PBT. For comparison purpose, the weight loss of PG1 normalized by the initial weight of PBT in PG1 is also included in the figure. It can be clearly seen in Fig. 1 that both formulations undergo one-step reaction at the same temperature range. The fact that glass-fibre does not change the decomposition of PBT confirms that it is a chemically inert material, which only acts, as seen in the cone calorimeter experiments, as a protection layer in the solid phase.

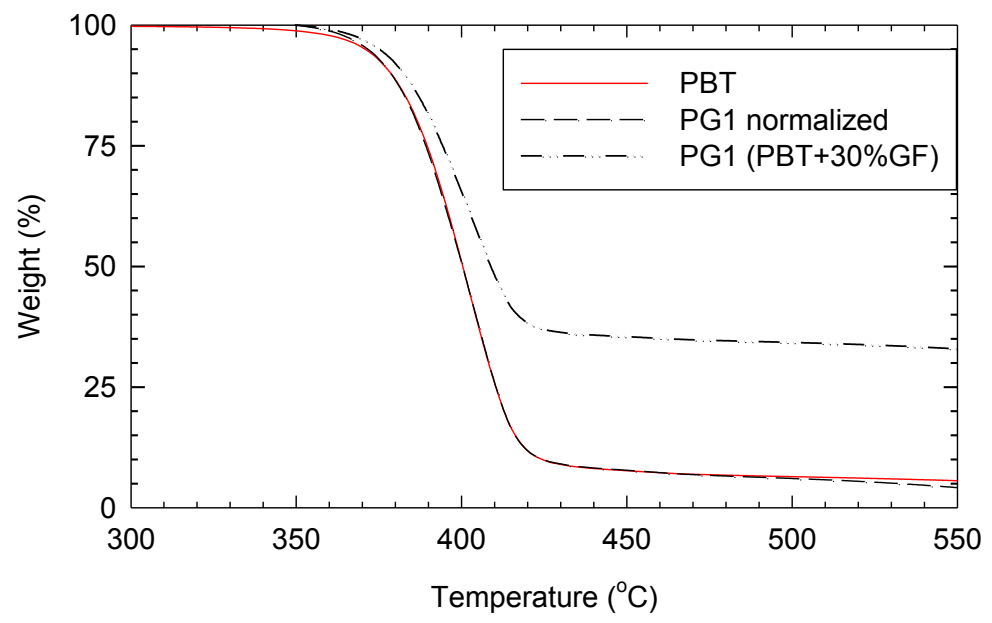

Fig. 1. Comparison of the mass loss (TGA) between glass-fibre enforced PBT (PG1) and neat PBT at 10 ${ }^{\circ} \mathrm{C} / \mathrm{min}$ in nitrogen.

Figure 2 presents a comparison of the mass loss (TGA) and mass loss rate (DTG) at $10{ }^{\circ} \mathrm{C} / \mathrm{min}$ for all formulations. The results at other heating rates are similar indicating the same pyrolysis kinetics. It seems that all FRs induce early decomposition of PBT, which may indicate some synergistic effect of FRs and PBT as both neat brominated polystyrene and Alpi degrade at higher temperatures as shown in Fig. 3. The interaction between brominated polycarbonate and $\mathrm{PBT}+\mathrm{GF}$ was reported in [8].

Table 2 shows the residue (wt. \%) in TGA at 500 and $1000{ }^{\circ} \mathrm{C}$. PG2 gives a residue of 33.0 and $29.1 \mathrm{wt} \%$ at 500 and $1000^{\circ} \mathrm{C}$, respectively. This formulation contains less glass-fibre than PG1, i.e. $25.5 \%(85 \%$ of $\mathrm{PBT}+\mathrm{GF} \times 30 \%$ of GF) which composes the major part of the residue. As shown in Fig. 3, BrPS degrades almost completely, and only a small amount of antimony trioxide acts in the solid phase (via $\mathrm{SbOBr}$ which 
facilitates the dissociation of $\mathrm{C}-\mathrm{Br}$ bonds [9]). Consequently, as the amount of residue of PG2 is higher than expected, it is concluded that there is an interaction between PBT and BrPS.

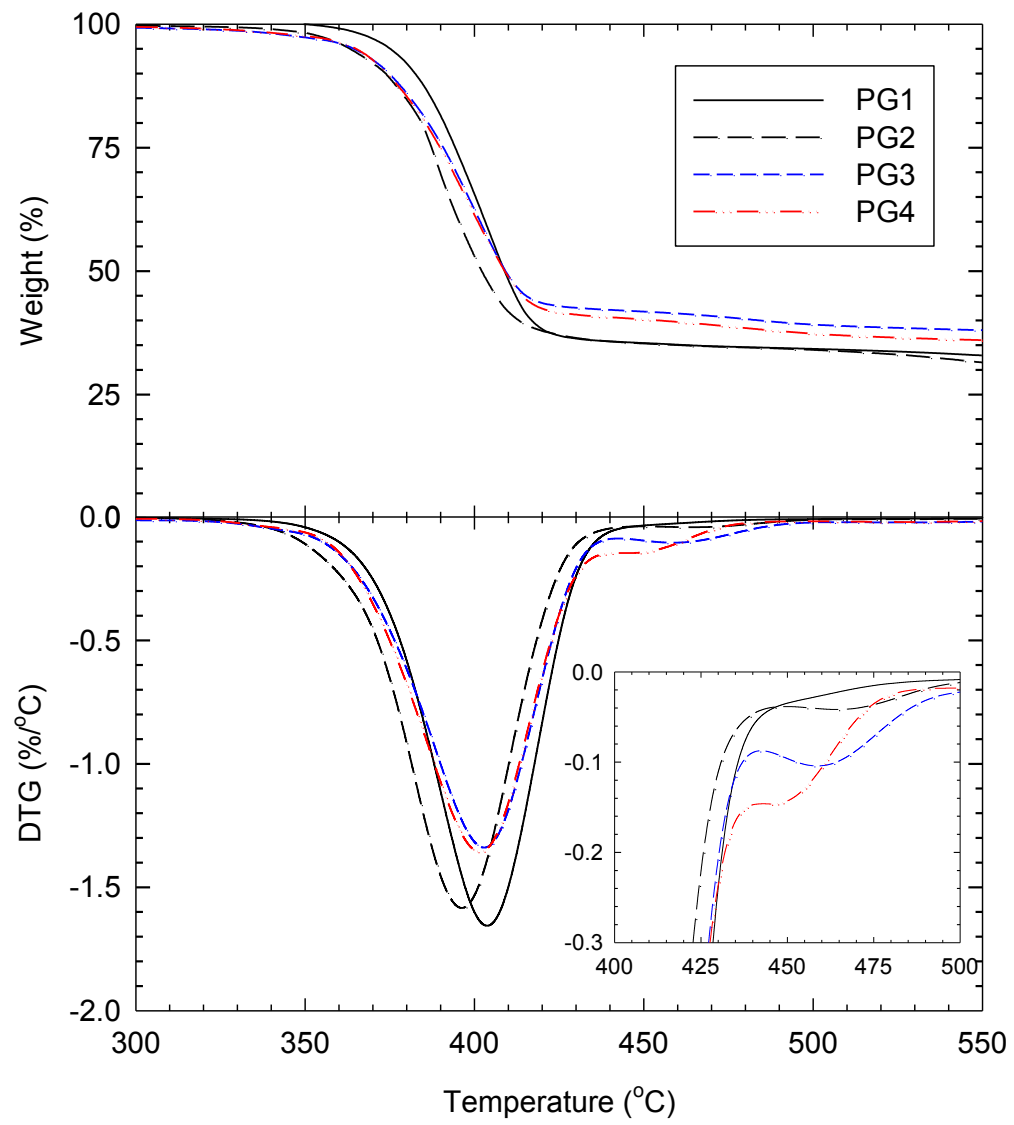

Fig. 2. TGA and DTG curves at $10^{\circ} \mathrm{C} / \mathrm{min}$ in nitrogen.

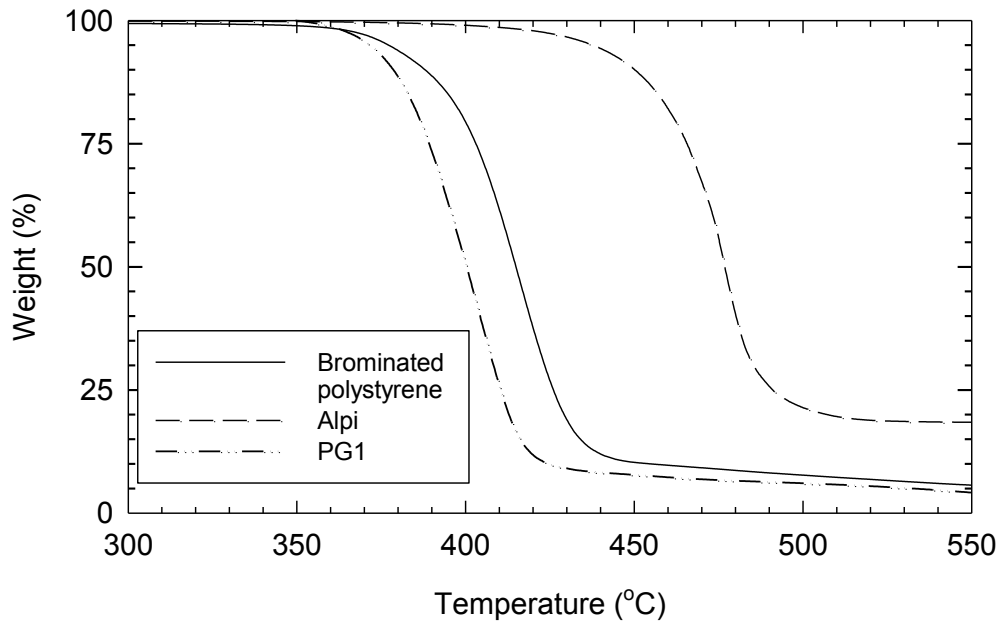

Fig. 3. TGA curves of brominated polystyrene and Alpi (PG1 as reference).

Table 2. Residue (wt \%) in TGA at 500 and $1000^{\circ} \mathrm{C}$

\begin{tabular}{|l|c|c|c|c|}
\hline \multicolumn{1}{|c|}{ Formulations } & PG1 & PG2 & PG3 & PG4 \\
\hline $500{ }^{\circ} \mathrm{C}$ & 34.2 & 33.0 & 36.9 & 35.6 \\
\hline $1000^{\circ} \mathrm{C}$ & 30.8 & 29.1 & 33.5 & 31.9 \\
\hline
\end{tabular}


For Alpi containing materials, an additional small decomposition step is observed at around $475^{\circ} \mathrm{C}$, which is due to the vaporization of Alpi as shown in Fig. 3. It was reported in [15] that the decomposition process of Alpi depends on experimental conditions (such as the size of the crucible and the mass of the sample) and that two different decomposition behaviours are observed depending on these conditions: vaporization of Alpi as a complete molecule (around $275^{\circ} \mathrm{C}$ ) or decomposition of Alpi $\left(435{ }^{\circ} \mathrm{C}\right.$ ). The amount of residue changes depending on the process. In our measurement for PG4, the second step at $475^{\circ} \mathrm{C}$ is due to the vaporization of Alpi while the change in weight slope during the first decomposition and the increase in residue are due to the action of decomposition products of Alpi.

The results of PG3 are similar to those of PG4, indicating that nanoclay does not affect the decomposition of the materials. As shown in [13-15], the primary effect of nanoclay is that it forms a protection char layer for neat polymers or enhances the char strength of FRs or intumescent coating and such physical actions of nanoclay cannot be observed for the thermally thin materials as tested by TGA; consequently the effect of nanoclay is minimal in micro-scale experiments. However as it will be shown later in the cone calorimeter results that nanoclay can have a significant effect on the fire retardancy when combined with Alpi.

\section{Limiting oxygen index (LOI) and UL94}

Table 3 summaries the LOI and UL94 results. The three fire retardants containing formulations are V0 rated while PG1 failed the UL94 test. This result highlights one of the drawbacks of the UL94 test as it cannot differentiate the behaviour of different fire retardants having the same acceptable V0 rating. For the LOI measurements, PG4 has the highest LOI (35.5\%), followed by PG3 (31.5\%), PG2 (28\%) and PG1 (19.5\%). The fact that Alpi alone achieves a higher LOI than Alpi combined with OMMT is somehow unexpected. This result indicates that although LOI measurement provides a numerical result convenient to rank materials, it does not correspond to an intrinsic material property becasue the LOI value depends on experimental characteristics such as heat of pyrolysis or effective heat transfer coefficient to the sample for instance. The complexity or the extinction process involved for LOI determination can be found in [17].

Table3. Results of limiting oxygen index (LOI) and UL 94 tests.

\begin{tabular}{|l|l|l|l|l|}
\hline \multicolumn{1}{|c|}{ Formulations } & \multicolumn{1}{c|}{ PG1 } & \multicolumn{1}{c|}{ PG2 } & \multicolumn{1}{c|}{ PG3 } & \multicolumn{1}{c|}{ PG4 } \\
\hline LOI (\%) & 19.5 & 28.0 & 31.5 & 35.5 \\
\hline UL-94 Vertical (nom 3.2mm) & Fail & V0 Pass & V0 Pass & V0 Pass \\
\hline
\end{tabular}

\section{Cone calorimeter}

\section{Visual observations}

After the tests, sample residues present different visual aspects depending on both the formulation and also on the external heat flux. For PG1 and PG2, small pores are visible on the surface of the residue and colour changes from white (high heat fluxes) to dark grey (below $30 \mathrm{~kW} / \mathrm{m}^{2}$ ). These residues are mainly composed of glass-fibre, as the weight of the residue is the same as the initial glass-fibre content. For PG3 and PG4, black residues were observed: for PG4, this carbonaceous char is bumpy and porous whereas it is smooth and stiff for PG3. Observed carbonaceous chars for PG3 and PG4 are an indication of solid phase action of Alpi and OMMT.

\section{Time to ignition}

Table 4 summarizes the average times to ignition (TTIs) in horizontal configuration. At heat fluxes lower than $45 \mathrm{~kW} / \mathrm{m}^{2}$, flashes were often observed prior to sustained combustion. The ignition behaviour of PG2 is noticeably different at these low heat fluxes-flashes were still observed but the sparkle igniter had to be maintained much longer when first flames appeared in order to reach sustained combustion. This illustrates the gas phase action of BrPS contained in PG2. At lower heat fluxes, all FRs seem efficient in delaying ignition. For PG2 and PG3, an increase of about $30 \%$ in TTI is observed at $22.5 \mathrm{~kW} / \mathrm{m}^{2}$ and $40 \%$ for PG4, compared to PG1. However, at higher heat fluxes PG2 actually has lower TTIs than PG1, indicating that the action of BrPS on TTI is less efficient with increasing heat flux. In comparison, Alpi with/without OMMT delays TTI with similar findings reported in [11,12], which showed that Alpi increases TTI of $\mathrm{PBT}+\mathrm{GF}$. However, as observed for BrPS, the action of Alpi decreases with increasing heat flux. It should 
be noted that by plotting time to ignition against external heat flux, it is possible to determine the critical heat flux as shown in Table 5, where the effective ignition and flammability properties are deduced.

Table 4. Averaged time to ignition at different heat fluxes in the horizontal cone calorimeter.

\begin{tabular}{|l|r|r|r|r|r|r|}
\hline Formulations & $\mathbf{2 2 . 5} \mathbf{k W} / \mathbf{m}^{\mathbf{2}}$ & $\mathbf{3 0 k W} / \mathbf{m}^{\mathbf{2}}$ & $\mathbf{4 5} \mathbf{k W} / \mathbf{m}^{\mathbf{2}}$ & $\mathbf{6 0 k W} / \mathbf{m}^{\mathbf{2}}$ & $\mathbf{7 5} \mathbf{k W} / \mathbf{m}^{\mathbf{2}}$ & $\mathbf{9 0 k W} / \mathbf{m}^{\mathbf{2}}$ \\
\hline PG1 & 228 & 101 & 44.5 & 26 & 15 & 12.5 \\
\hline PG2 & 335 & 116 & 43 & 26 & 12 & 9.7 \\
\hline PG3 & 329 & 158 & 55 & 32 & 14.5 & 11.2 \\
\hline PG4 & 390 & 150 & 51.5 & 29 & 16 & 9.3 \\
\hline
\end{tabular}

Mass loss rate

Figure 4 shows a comparison of the mass loss rate at $60 \mathrm{~kW} / \mathrm{m}^{2}$. The trends of the MLR follow those of typical charring materials. Namely, the mass loss rate (i) increases to reach the first peak, (ii) decreases rapidly to reach a plateau, (iii) increases again to form the second peak and (iv) finally decreases when most of the material is consumed. The decrease of the mass loss rate after the first peak is due to the formation of a surface layer as a result of accumulation of glass-fibre [20]. It reduces the pyrolysis gas supply to the combustion zone by retarding heat transfer from the surface material to the virgin zone owing to re-radiation losses from the surface consisting mainly of glass-fibre. The second peak is due to the insulated backside. When the heat reaches the insulated back surface, there is an accumulation of energy due to the insulation, which results in an increase of the mass loss rate.

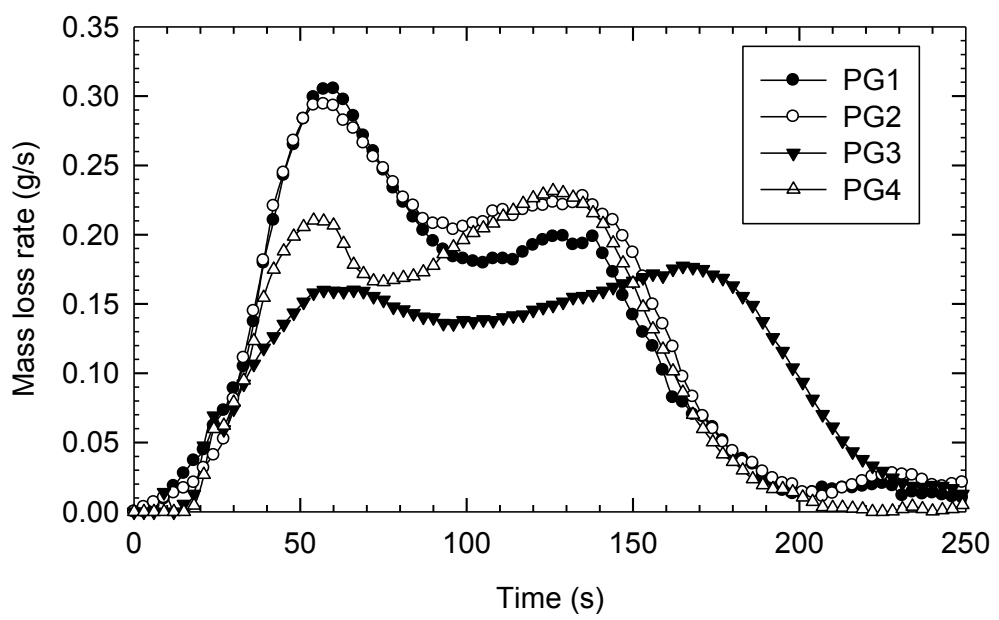

Fig. 4. Mass loss rate at $60 \mathrm{~kW} / \mathrm{m}^{2}$ in the horizontal cone calorimeter.

The MLRs of PG1 and PG2 are similar, which indicates that the BrPS combined with $\mathrm{Sb}_{2} \mathrm{O}_{3}$ has little effect in the solid phase. For PG4, a thin char layer is formed on the sample surface, which could be responsible for the reduction in the first peak MLR. When OMMT is added, the MLR is reduced further by between 30 and $50 \%$ depending on the external heat flux owing to the increased strength of the char formed by glassfibre and Alpi in the presence of OMMT. The pyrolysis process is however prolonged because the total mass loss is similar between PG3 and PG4. A much rigid and solid-like char was observed for PG3 compared to the thin char layer for PG4.

\section{Heat release rate}

Figure 5 shows the HRR (normalized by the exposed surface area) at $60 \mathrm{~kW} / \mathrm{m}^{2}$. Interestingly, while the mass loss rates of PG1 and PG2 are similar (see Fig. 4), their heat release rates are considerably different. BrPS reduces the first peak HRR by more than $70 \%$. This result indicates a strong gas phase action of $\mathrm{BrPS}$, which consists in interacting of bromine with highly reactive free-radical species such as $\mathrm{H} \bullet$ and $\mathrm{O} \bullet$ by slowing down or stopping the cascade-chain mechanism of the combustion [21]. Antimony Trioxide 
interacts with BrPS and improves its decomposition. Among all formulations, PG2 produces the lowest HRRs without prolonging the burning process compared to PG1.

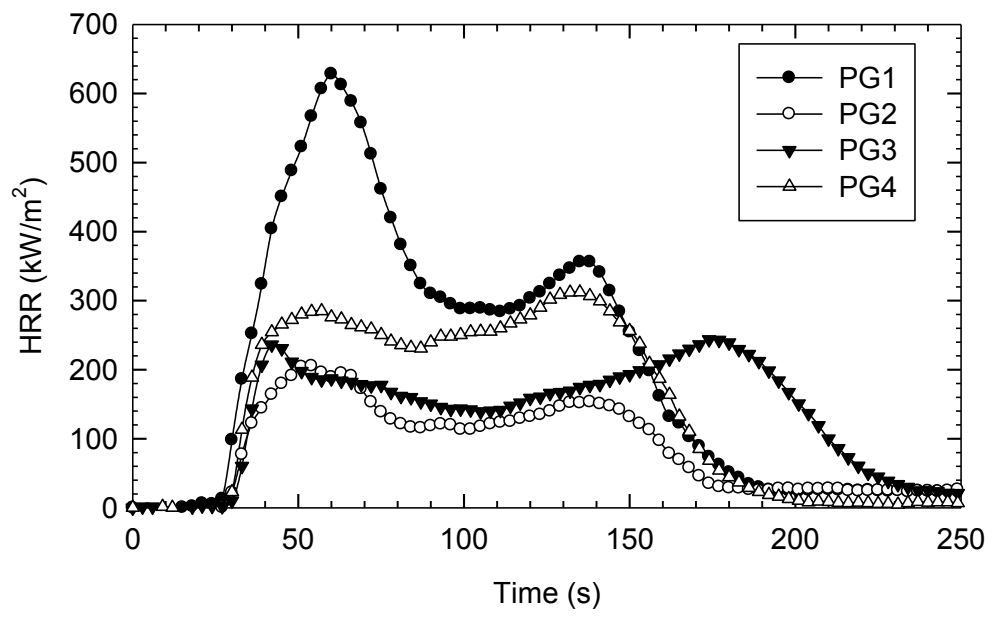

Fig. 5. Heat release rate at $60 \mathrm{~kW} / \mathrm{m}^{2}$ in the horizontal cone calorimeter.

For PG4, there is a reduction of about $60 \%$ at its first peak HRR. However its second peak HRR is close to that of PG1. The present results are similar to those reported in [15], where a decrease of about $45 \%$ in the first peak HRR was achieved whilst no difference was noted for the second peak HRR when $20 \%$ Alpi was used in $\mathrm{PBT}+\mathrm{GF}$.

For PG3, there is a further reduction of the HRR compared to PG4. The first peak HRR for PG3 is comparable with that for PG2, however with a prolonged burning process. The reduction of the HRRs by PG3 in comparison to PG4 is mainly due to the reduction in the MLR as shown in Fig. 4.

\section{Effective heat of combustion $\Delta H_{c, \text { eff }}$}

Figure 6 presents the effective heat of combustion (EHoC), calculated by dividing the total heat released (THR) by the total mass lost and then normalized by the PBT+GF weight content for each formulation. PG1 has the highest EHoC with an average of $15.5 \mathrm{~kJ} / \mathrm{g}$. PG2 has the lowest EHoC ranging from 5.6 to 8.8 $\mathrm{kJ} / \mathrm{g}$ depending on the external heat flux. It corresponds to a decrease of about $55 \%$ compared to PG1. This reduction illustrates the dominant gas phase action of BrPS. Although the total mass lost for PG2 is the same for all heat fluxes, its EHoC increases slightly with the heat flux. The efficiency of the gas phase action of BrPS seems to decrease with increasing heat flux. The gas phase action of BrPS is also illustrated by the difficulty in igniting PG2 samples described previously and local extinction at lowest heat fluxes. PG4 shows a decrease of about $15 \%$ in $\mathrm{EHoC}$ which also indicates an action of the phosphorous FR in the gaseous phase with similar results reported in [15]. PG3 has a similar EHoC to PG4 although PG3 burning process lasts longer with lower MLR. OMMT reduces the HRR but does not change the total amount of heat released. The action of the OMMT is only physical.

It should be mentioned that the values obtained in this work are slightly lower than those reported in the literature. For example, $22 \mathrm{~kJ} / \mathrm{g}$ was reported in [21] for pure PBT and $21 \mathrm{~kJ} / \mathrm{g}$ for PBT $+\mathrm{GF}$ [18]. This could be due to the difference in the samples used in these studies as glass-fibre should not affect the fire behaviour of PBT. 


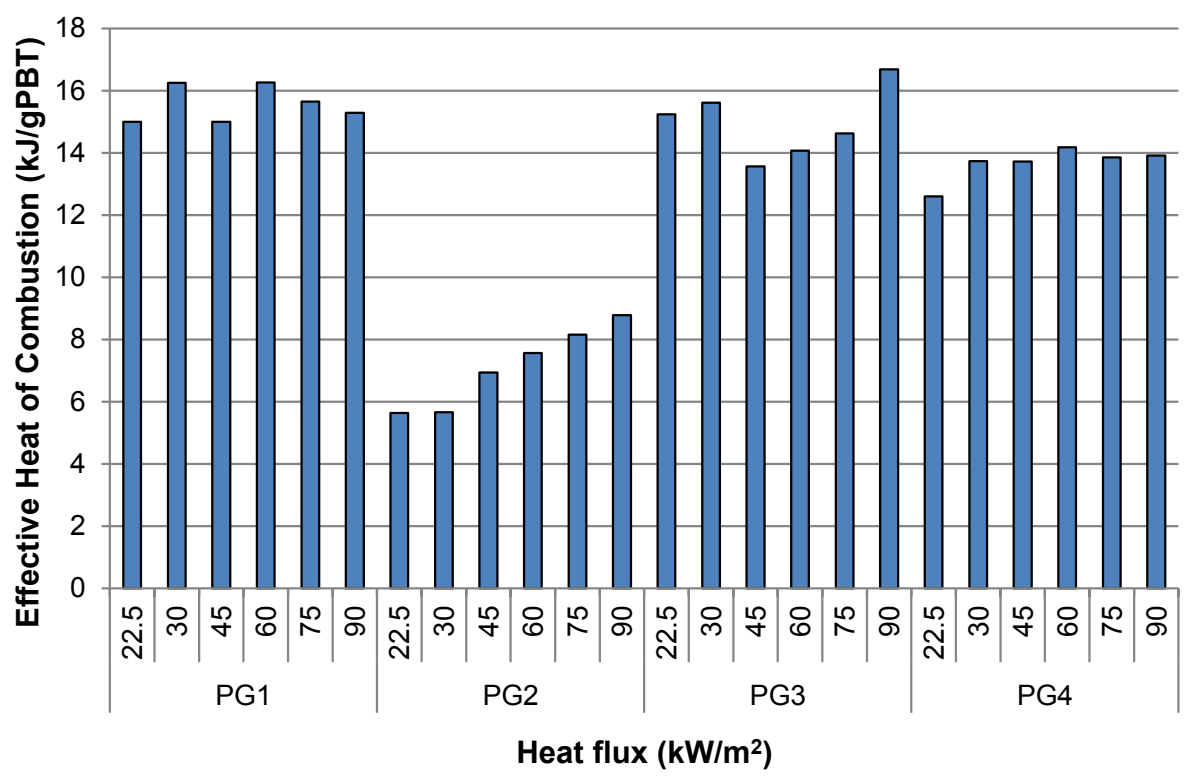

Fig. 6. Comparison of effective heat of combustion $\left(\mathrm{kJ} / \mathrm{g}_{\mathrm{PBT}}\right)$ at six heat fluxes, calculated by dividing the total heat released by the PBT content in each formulation, in the horizontal cone calorimeter.

\section{Production of smoke and carbon monoxide}

Carbon monoxide, and smoke yields were calculated from the pre-ignition period until the flame goes out. The smoke production rate was calculated as the volume flow rate in the exhaust duct times the extinction coefficient. Results are plotted in Figs. 7-9.

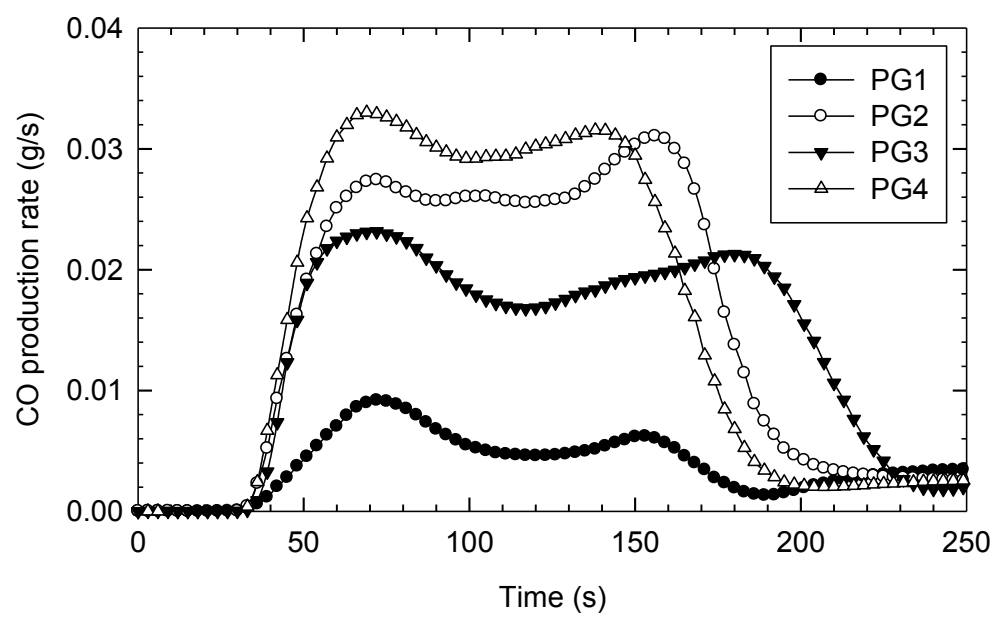

Fig. 7. CO production rate $(\mathrm{g} / \mathrm{s})$ at $60 \mathrm{~kW} / \mathrm{m}^{2}$ in the horizontal cone calorimeter.

As expected, PG1 has the lowest $\mathrm{CO}$ and smoke yields and production rates. It demonstrates a more complete combustion than the other three formulations. The combustion of PG2 yields about $20 \%$ more smoke than other FR formulations and 55\% more than PG1. Its peak values of smoke production rates are 2.5 times higher than those obtained for PG1. PG4 yields more than $15 \%$ of CO than PG2 and almost $80 \%$ more than PG1. CO is produced $15 \%$ more by PG4 than by PG2. It is generally considered that an increase in smoke and $\mathrm{CO}$ production by a factor of more than two is the consequence of a suppressed total oxidation process and is synonym of a radical trapping mechanism. Consequently BrPS and Alpi may act in the gas phase as radical scavengers. When OMMT is combined with Alpi in PG3, the same amount of CO and smoke is produced as when Alpi is used alone. However, the use of OMMT reduces the rate at which these species are released by $45 \%$ and $25 \%$ for $\mathrm{CO}$ and smoke respectively. 


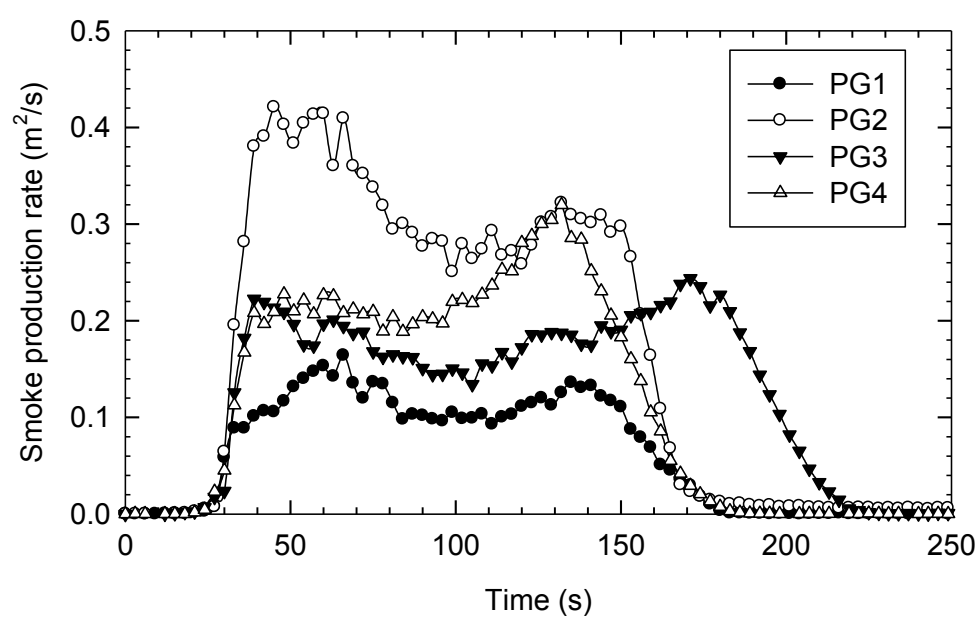

Fig. 8. Smoke production rate $\left(\mathrm{m}^{2} / \mathrm{s}\right)$ at $60 \mathrm{~kW} / \mathrm{m}^{2}$ in the horizontal cone calorimeter.

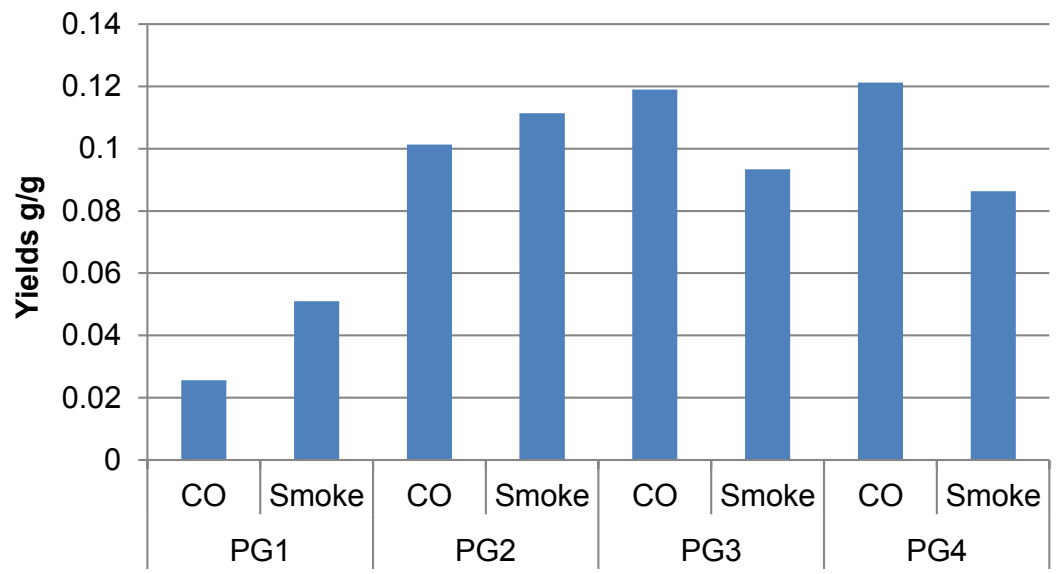

Fig. 9. Average $\mathrm{CO}$ and smoke yields at all heat fluxes in the horizontal cone calorimeter.

\section{Vertical tests}

Figure 10 shows a comparison of the MLRs and HRRs at $75 \mathrm{~kW} / \mathrm{m}^{2}$ in horizontal and vertical orientations. The results show that both MLR and HRRs are about 30\% lower in vertical orientation than in horizontal orientation. The action of BrPS and Alpi is however similar for both cases. The difference in two orientations could be attributed to the differences in convective heat transfer coefficient and flame radiation to the sample. However, the change in the flame heat flux alone is not sufficient to explain the decrease in mass loss rate as the flame heat flux is considered to be small (estimated to be about $10 \mathrm{~kW} / \mathrm{m}^{2}$ ) compared to the external heat flux. Another possible explanation could be a change in the burning behaviour in vertical orientation (for example in the way how the polymer flows and pyrolyses) because a difference in the total mass lost was also observed between horizontal and vertical orientations, which shows the total mass lost in vertical orientation is systematically lower than that in horizontal orientation. 

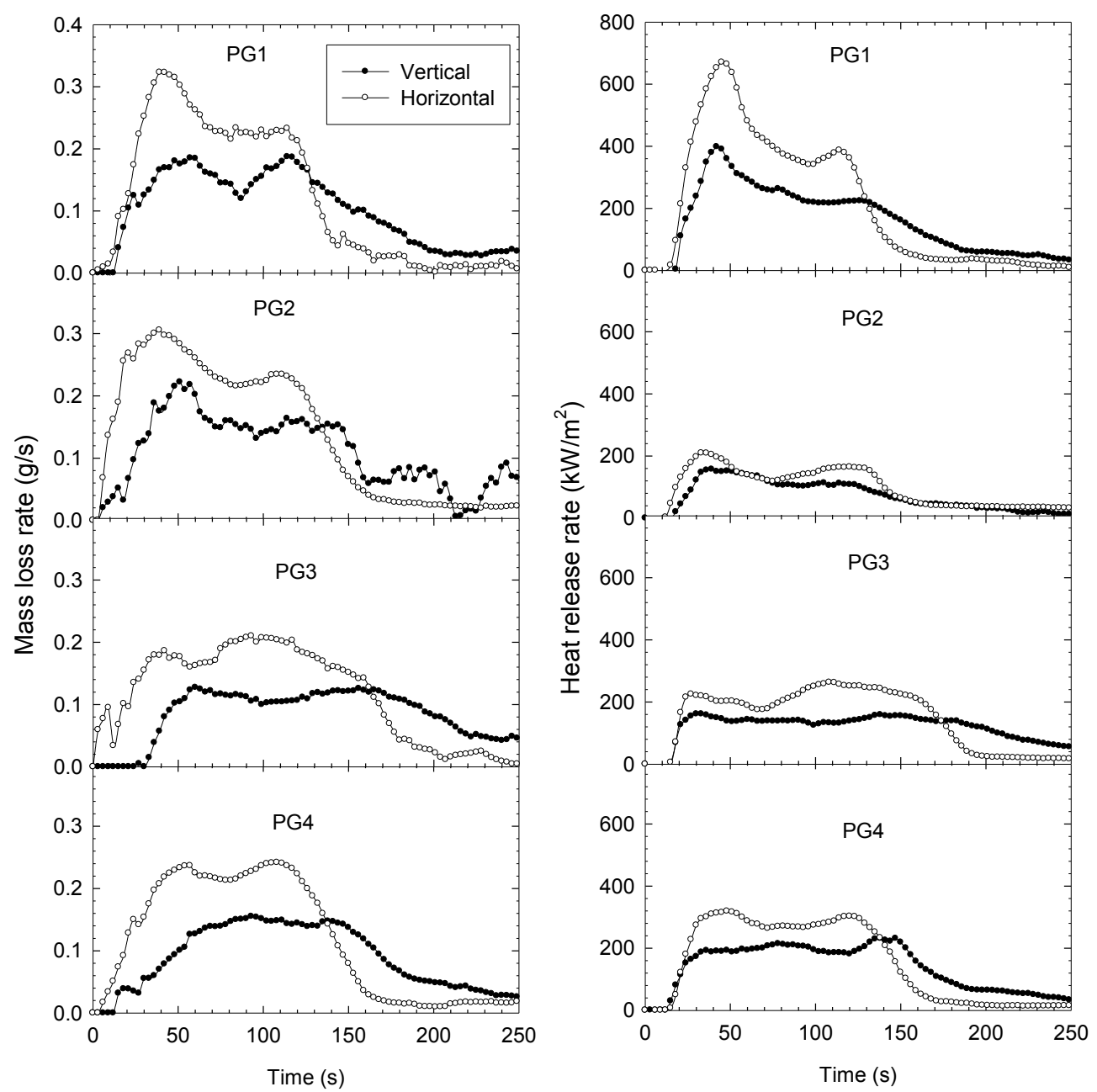

Figure 10. Comparison of MLRs and HRRs at $75 \mathrm{~kW} / \mathrm{m}^{2}$ between horizontal and vertical tests.

\section{Modelling of pyrolysis of $P B T+G F$}

By plotting the time to ignition against the heat flux it is possible to determine the effective ignition and flammability properties [23]. The results are summarized in Table 5. As mentioned earlier, the action of glass-fibre can be considered similar to that of a char layer, which allows the prediction of the pyrolysis rate of $\mathrm{PBT}+\mathrm{GF}$ using the methodology that have been previously developed for polymer nanocomposites [13]. A brief description of the methodology is given here below whereas detailed formulations can be found in [13].

Table 5. Effective ignition properties determined from the ignition tests in the cone calorimeter.

\begin{tabular}{|c|c|c|c|c|c|c|c|}
\hline Formulation & $\begin{array}{c}\rho \\
\left(\mathrm{kg} / \mathrm{m}^{3}\right)\end{array}$ & $\begin{array}{c}\alpha \\
\left(\mathrm{m}^{2} / \mathbf{s}\right)\end{array}$ & 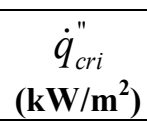 & $\begin{array}{l}T_{i g} \\
(\mathbf{K})\end{array}$ & $\begin{array}{c}k \\
(\mathbf{W} / \mathbf{m} \cdot \mathbf{K})\end{array}$ & $\begin{array}{c}c \\
(\mathrm{~J} / \mathrm{kg} \cdot \mathrm{K})\end{array}$ & $\begin{array}{c}k \rho c \\
\left(k J^{2} / \mathrm{m}^{4} \cdot \mathrm{K}^{2} . \mathrm{s}\right)\end{array}$ \\
\hline PG1 & 1520 & $4.9 \times 10^{-8}$ & 12.2 & 374 & 0.17 & 2215 & 0.56 \\
\hline PG2 & 1610 & $5.8 \times 10^{-8}$ & 18.4 & 452 & 0.14 & 1490 & 0.33 \\
\hline PG3 & 1495 & $5.1 \times 10^{-8}$ & 19.9 & 469 & 0.13 & 1770 & 0.36 \\
\hline PG4 & 1490 & $5.5 \times 10^{-8}$ & 22.5 & 494 & 0.12 & 1520 & 0.28 \\
\hline
\end{tabular}

Due to the shielding effect of glass-fibre, the heat flux on the interface of the glass-fibre surface layer and virgin material is only a fraction of the heat flux on the surface for the case when there is no surface layer. 
This allow to define a heat flux ratio [13], i.e. the ratio of the heat flux on the surface for the case when there is no surface layer to that at the interface for the case of PBT+GF. By definition, this heat flux ratio should be equal to or larger than one. This heat flux ratio can be calculated by solving one-dimensional conduction equation with the use of the experiment mass loss data and effective ignition and flammability properties given in Table 5 .

$\operatorname{ratio}_{f l u x}(t)=\frac{\dot{q}_{\text {net_o }}^{\prime \prime}}{\dot{q}_{\text {net }}^{\prime \prime}(t)}$

where $\dot{q}_{n e t_{-} 0}^{\prime \prime}$ is the net incoming heat flux on the surface for the case when there is no surface and $\dot{q}_{n e t}^{\prime \prime}(t)$ is the actual heat flux at the interface of the surface (nanoparticle) layer and virgin material in the presence of the surface layer. $\dot{q}_{\text {net_o }}^{\prime \prime}$, can be calculated using the energy balance on the surface with the surface temperature being the ignition temperature as:

$\dot{q}_{\text {net_o }}^{\prime \prime}=\dot{q}_{\text {cone }}^{\prime \prime}+\dot{q}_{\text {flame }}^{\prime \prime}-\sigma T_{i g}^{4}-h_{c}\left(T_{i g}-T_{\text {amb }}\right)$

$\dot{q}_{\text {net }}^{\prime \prime}(t)$ can be found by combining experimental mass loss data and the conductive heat flux on the surface from the numerical model as:

$\dot{q}_{n e t}^{\prime \prime}(t)=-\left.k \frac{\partial T}{\partial x}\right|_{x=0}+\dot{m}^{\prime \prime}(t) L$

where L is the heat of pyrolysis of PG1, which was assumed to be the same as that of pure PBT [24], i.e., $1000 \mathrm{~kJ} / \mathrm{kg}$, because glass-fibre does not affect the decomposition of PBT as confirmed in the TGA results.

The calculated heat flux ratio is plotted against the pyrolysed depth (i.e., the depth of the material that has pyrolysed, $\left.\delta_{p y r o},=\int_{0}^{t} \dot{m}^{\prime \prime}(\tau) d \tau / \rho\right)$ in Fig. 11 for a heat flux of $60 \mathrm{~kW} / \mathrm{m}^{2}$, where we note that it is nearly one at the beginning and then increases almost linearly after the initial stage.

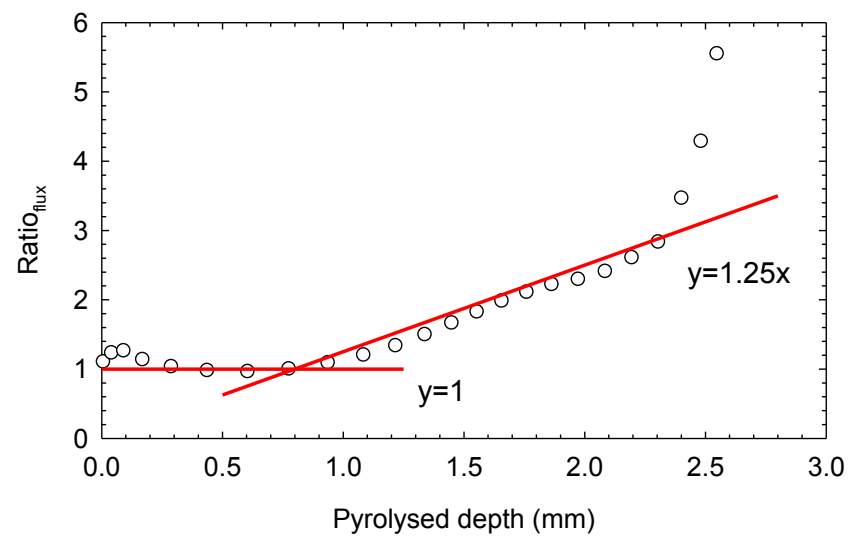

Fig. 11. Calculated instantaneous heat flux ratio, ratio flux , against the pyrolysed depth, $\delta_{\text {pyro }}$, at $60 \mathrm{~kW} / \mathrm{m}^{2}$ (sample thickness is $2.9 \mathrm{~mm}$ ). Two lines represent the best fits of the calculated results.

These results imply that the reduction of the heat flux at the interface is proportional to the amount of glassfibre on the surface. Using curving fitting, the following relationship between the heat flux ratio and pyrolysed depth was deduced. 


$$
\begin{array}{ccc}
\text { Ratio }_{\text {flux }}=1 & \text { for } & \delta_{\text {pyro }}>0.8 \mathrm{~mm} \\
\text { Ratio }_{\text {flux }}=1.25 \delta_{\text {pyro }} & & \delta_{\text {pyro }}<0.8 \mathrm{~mm}
\end{array}
$$

Subsequently, Equation 1, along with the effective properties, can be used to predict the pyrolysis rate at other heat fluxes [13] as:

$$
\dot{m}^{\prime \prime}(t)=\frac{\dot{q}_{\text {cone }}^{\prime \prime}+\dot{q}_{\text {flame }}^{\prime \prime}-O T_{i g}{ }^{4}}{\text { ratio }_{\text {flux }} \cdot L}
$$

In Fig. 12, the predicted pyrolysis rates are compared to the experimental ones. The trends of the two sets of data are similar and the predictions are also in reasonably quantitative agreement with the measurements. This result confirms the earlier proposition that the effect of glass-fibre is similar to a char layer and its fire protection performance improves when the depth of the glass-fibre layer increases during pyrolysis.

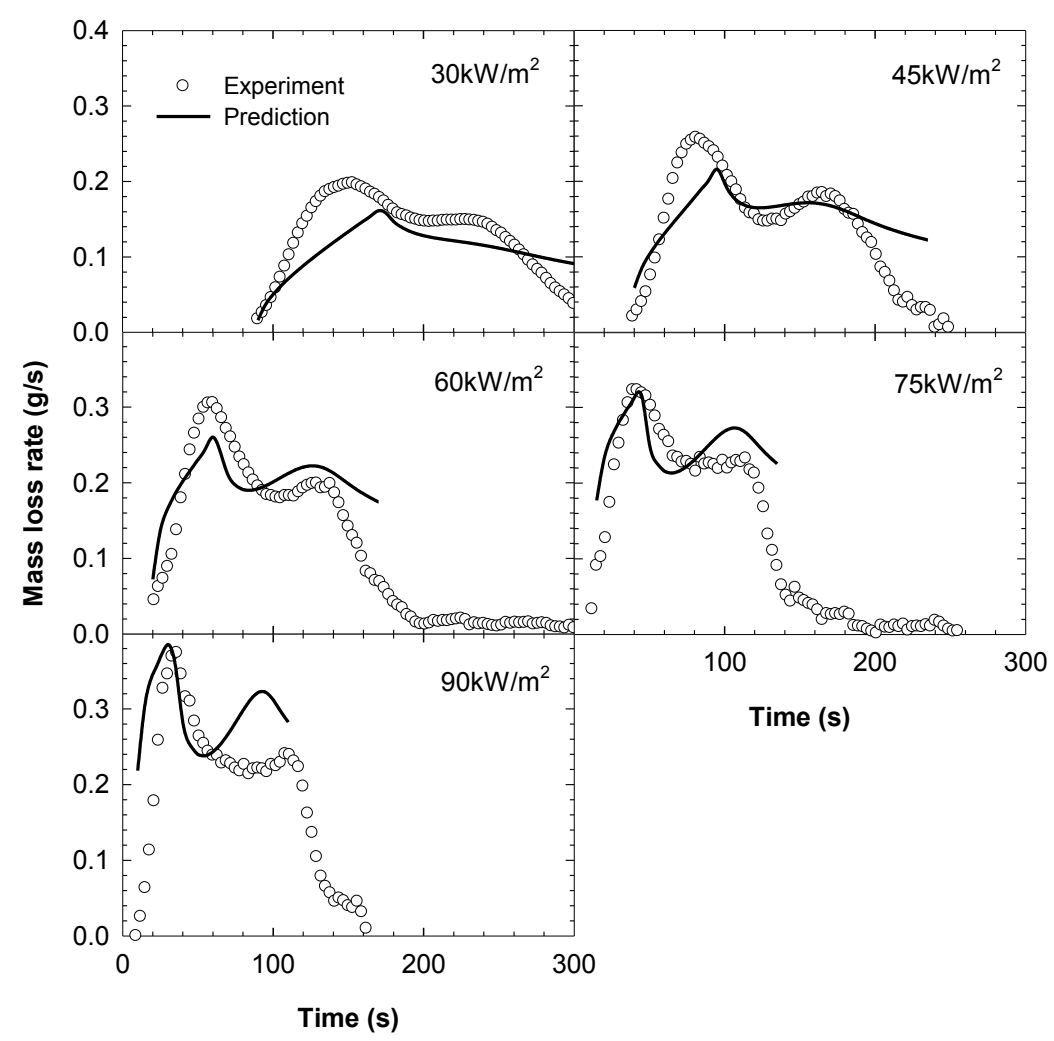

Figure 12. Comparisons of experimental and predicted mass loss rates of PG1 at different heat fluxes.

\section{CONCLUSIONS}

Glass-fibre reinforced PBT was fire retarded with a brominated fire retardant (BFR), namely brominated polystyrene (BrPS) combined with antimony trioxide, and two halogen-free fire retardants (HFFRs), Alpi with and without OMMT. The fire retardancy of these compound materials was assessed using TGA, LOI, UL94 and the cone calorimeter. The major conclusions of this work are:

- All fire retardants accelerate the decomposition of PBT $+\mathrm{GF}$ in TGA indicating synergistic effect between fire retardants and $\mathrm{PBT}+\mathrm{GF}$.

- All fire retarded formulations achieved V0 rating in the UL94 vertical test for $3.2 \mathrm{~mm}$ thick samples, whereas the neat PBT + GF (PG1) failed the test. For LOI tests, Alpi alone (PG4) has the highest LOI, followed by Alpi with OMMT (PG3), brominated polystyrene (PG2) and PG1. 
- Brominated polystyrene shows strong action in the gaseous phase because the combustion is incomplete and the heat of combustion decreases. Therefore, it achieves the lowest heat release rate (HRR) with a reduction of more than $70 \%$ compare to PG1 even though it has nearly the same mass loss rate (MLR) as PG1. However, it produces excessive CO, smoke and unburned pyrolysing gases;

- For PG4, there is a reduction of both HRR and MLR indicating that Alpi acts both in the condensed phase by modifying the residue (glass-fibre plus residue from Alpi, Figs. 4 and 5) and in the gaseous phase by decreasing the effective heat of combustion. The decrease of the HRR is however less than that by brominated polystyrene. Although the Alpi formulation produces less smoke than the brominated one (PG2), it releases more CO. When OMMT is combined with Alpi (PG3), there is a further reduction in the HRR and MLR. The HRR of PG3 is similar to that of PG2, as a result of reduced MLR. Yields of CO and smoke are comparable to those of PG4. The combination of Alpi and OMMT appears to be the best alternative to the brominated FR in PBT+GF because the strength and effectiveness of the residue by glass-fibre and Alpi residue increases in the presence of OMMT.

- For vertical cone calorimeter tests, lower HRRs/MLRs were recorded for all formulations possibly due to reduced flame heat flux and also to a change in the burning behaviour because lower total mass loss was observed in vertical orientation. No dripping was observed for all formulations.

- The methodology previously developed for charring materials and polymer nanocomposites was used to quantify the effect of glass-fibre and to predict the pyrolysis of PG1 and the results indicated that glass-fire acts only in the solid phase as a protection layer.

- The present study also highlights the limitations of commonly used UL94 and LOI tests, because these tests (UL94 and LOI) do not provide a way to discriminate the behaviour of these materials in real fires. For example, UL94 test cannot differentiate materials with the same rating (V0 in this case). The LOI results in this work indicate that the formulation containing only Alpi (PG4) has the highest LOI. However, the cone calorimeter results clearly show that PG2 and PG3 have similar HRRs, which are lower than those of PG4. In addition, LOI and UL94 tests cannot take into account smoke and CO production, which are important hazards in fires.

\section{ACKNOWLEGEMENTS}

The authors acknowledge the EU for financially supporting the ENFIRO project under Grant No 226563. The authors also thank Dr P Patel, Mr P. Clarke, and Dr P Cusack at ITRI Innovation for providing the LOI and UL94 data and Mr W Veighey for helping with the Cone experiments.

\section{REFERENCES}

[1] Hites, RA., (2004) Polybrominated diphenyl ethers in the Environment and in People: a Metaanalysis of Concentrations, Environ. Sci. Techno. 38: 945-956.

[2] Fängström, B., Strid, A., Grandjean, P., Weihe, P., and Bergman A., (2005) A Retrospective Study of PBDEs and PCBs in Human Milk from the Faroe Islands, Environ. Health 4: 12

[3] Schecter, A., Päpke, O., Tung, K., Joseph, J., Harris, T., Dahlgren, J., Polybrominated diphenyl ether flame retardants in the U.S. Population: Current levels, Temporal Trends, and Comparison with Dioxins, Dibenzofurans, and Polychlorinated Biphenyls, J. Occup. Environ. Med. 47: 199211

[4] She, J., Holden, A., Sharp, M., Tanner, M., Williams-Derry, C., and Hooper, K., (2007) Polybrominated diphenyl ethers (PBDEs) and Polychlorinated biphenyls (PCBs) in Breast Milk from the Pacific Northwest, Chemosphere 67: 307-317

[5] Schantz, S., Widholm, J., Rice, D., (2003) Effects of PCB Exposure on Neuropsychological Function in Children, Environ. Health Perspect. 111: 357-576.

[6] Stapleton, H., Dodder, N., Offenberg, J., Schantz, M., Wise, S., (2004) Polybrominated Diphenyl Ethers in House Dust and Clothes Dryer Lint, Environ. Sci Technol. 39: 925-931

[7] Dingemans, M., Ramakers, G., Gardoni, F., Van Kleef, R., Bergman, A., Di Luca, M., Van den Berg, M., Westerink, R., and Vijverberg, H., (2008) Neonatal Exposure to Brominated Flame 
Retardant BDE-47 Reduces Long-term Potentiation and Postsynpatic Protein Levels in Mouse Hippocampus, Environ. Health Perspect, 115: 865-870.

[8] Sato, H., Kondo, K., Tsuge, S., Ohtani, H., and Sato, N., (1998) Mechanisms of Thermal Degradation of a Polyester Flame-retarded with Antimony Oxide/brominated Polycarbonate Studied by Temperature-programmed Analytical Pyrolysis, Polym. Degrad. Stab. 62: 41-48

[9] Lewin M. (2001) Synergism and Catalysis in Flame Retardancy of Polymers, Polymers for Advanced Technologies 12, pp. 215-222.

[10] Xiao, W., He, P., He, B. and Zhang, F., (2003) Study on the flame-retarding mechanism of brominated polyystyrene waste in cured epoxy resin, Journal of Fire Science, 21: 319-329.

[11] Gallo, E., Braun, U., Schartel, B., Russo, P. and Acierno, D., (2009) Halogen-free flame retarded poly(butylene terephthalate) (PBT) using metaL oxides/PBT nanocomposites in combination with aluminium phosphinates, Polym. Degrad. Stab., 94: 1245-1253.

[12] Samyn, F. and Bourbigot, S., (2012) Thermal decomposition of flame retarded formulations PA6/aluminum phosphinate/melamine polyphosphate/organomodified clay: Interactions between the constituents?, Polymer Degradation and Stability, 97: 2217-2230.

[13] Zhang, J., Delichatsios, M., and Bourbigot, S., (2009) Experimental and Numerical study of the Effects of Nanoparticles on Pyrolysis of a Polyamide 6 (PA6) Nanocomposite in the Cone Calorimeter, Combustion and Flame, 156(11): 2056-2062.

[14] Zhang, J., Hereid, M., Hagen, M., Bakirtzis, D., Delichatsios, M., Fina, A., Castrovinci, A., Camino, G., Samyn, F., and Bourbigot, S., (2008) Effects of Nanoclay and Fire Retardants on Fire Retardancy of a Polymer Blend of EVA and LDPE, Fire Safety Journal 44: 504-513.

[15] Zhang J, Delichatsios, M., McKee, M. and Ukleja, S. (2011) Experimental Study of Burning Behaviours of Intumescent Coating and Nanoparticles Applied on Flaxboard, Journal of Fire Science, 29(6), 519-531

[16] de Ris, J., and Khan, M., (2000) A Sample Holder for Determining Material Properties, Fire and Materials, 24: 219-226

[17] Suzanne, M., Delichatsios, M., and Zhang, J., (2011) Prediction of the Limiting Oxygen Index Using Simple Flame Extinction Theory and Material Properties Obtained From Bench Scale Measurements, Fire Safety Science 10: 375-387.

[18] Braun, U., Schartel, B., (2008) Flame retardancy Mechanisms of Aluminium Phosphinate in Combination with Melamine Cyanurate in Glass-fibre-reinforced Poly(1,4-butylene terephthalate), Macromolecular Materials and Engineering, 293: 206-217

[19] Braun, U., Bahr, H., Sturm, H., Schartel, B., (2008) Flame Retardancy Mechanisms of Metal Phosphinates and Metal Phosphinates in Combination with Melamine Cyanurate in Glass-fber reinforced poly(1,4-butylene terephtalate): the Influence of Metal Cation, Polymers for Advanced Technologies 19: 680-692

[20] Casu, A., Camino, G., De Giorgi, M., Flath, D., Laudi, A, and Mornone, V., (1998) Effect of Glass Fibres and Fire Retardant on the Combustion Behaviour of Composites, Glass Fibrespoly(butylene terephthalate), Fire and Materials 22: 7-14

[21] Lewin, M., Weil, E., Fire Retardant Materials, Woodhead Publishing Ltd, 2001.

[22] Brehme, S., Schartel, B., Goebbels, J., Fischer, O., Pospiech, D., Bykov, Y., Döring, M., (2011) Phosphorus Polyester Versus Aluminum Phosphinate in poly(butylene terephthalate) (PBT): Flame Retardancy Performance and Mechanisms, Polym. Degrad. Stab. 96: 875-884

[23] Delichatsios, M.A., (2005) Piloted Ignition Times, Critical Heat Fluxes and Mass Loss Rates at Reduced Oxygen Atmospheres, Fire Safety Journal 40:197-212

[24] Zhang, J., and Delicahtsios, M.A., (2010) Further Validation of a Numerical Model for Prediction of Pyrolysis of Polymer Nanocomposites in the Cone Calorimeter, Fire Technology 46:307-319 